\title{
Theoretical Derivation of Thermal Value Equations for Heating Furnaces
}

\author{
Hainan Wu, Wenqiang Sun*, Jiuju Cai \\ Institute of Thermal and Environmental Engineering, Northeastern University, Shenyang, China \\ Email: ${ }^{*}$ neu20031542@163.com
}

Received March 22, 2012; revised April 19, 2012; accepted May 2, 2012

\begin{abstract}
Based on thermal value theory, the aim of this paper is to deduce the theoretical formulas for evaluating the energy effective utilization degree in technological pyrological processes exemplified by metallurgical heating furnaces. Heat transfer models for continuous heating furnaces, batch-type heating furnaces, and regenerative heating furnaces are established, respectively. By analyzing the movement path of injected infinitesimal heat attached on steel or gas, thermal value equations of continuous, batch-type, and regenerative heating furnaces are derived. Then the influences of such factors as hot charging, gas preheating and intake time of heat on energy effective utilization degree are discussed by thermal value equations. The results show that thermal value rises with hot charging and air preheating for continuous heating furnaces, with shorter intake time when heat is attached on steel or longer intake time when heat is attached on gas for batch-type heating furnaces and that with more heat supply at early heating stage or less at late stage for regenerative heating furnaces.
\end{abstract}

Keywords: Thermal Value; Continuous Heating Furnace; Batch-Type Heating Furnace; Regenerative Heating Furnace; Energy Utilization Degree; Heat Transfer

\section{Introduction}

When studying thermal science and engineering, two types of energy utilization processes with different characteristics should be clearly distinguished. One is energy conversion processes; the other is technological pyrological processes [1]. In energy conversion processes, main feedstock and product are both energetic materials; e.g., feedstock is coal and product is electric in thermal power generation process. But neither material nor product is energy in technological pyrological processes, such as metallurgical production process in which feedstock is ore and product is metal and energy is just necessary for pushing the smelting process.

Traditionally, thermal efficiency has been used to evaluate the energy effective utilization degree of energy conversion processes [2,3]. However, thermal efficiency for technological pyrological process is different from that of energy conversion process [1]; and a conflict between thermal efficiency and specific energy consumption appears in some cases $[4,5]$. In this paper, heating furnaces in metallurgical industry, as technological facilities, are selected to study the evaluation method for energy utilization processes. To solve the conflict mentioned above, Prof. Ren [6] proposed thermal value the-

\footnotetext{
"Corresponding author.
}

ory combining energy conservation principle and heat transfer theory to evaluate the energy effective utilization degree in technological pyrological processes. It has been extended and investigated that thermal value theory is a theory on energy-saving and production-increasing for heating furnaces $[5,7]$.

The remainder of the paper is organized as follows: first, the definition of thermal value is briefly introduced. Then, a detailed derivation and discussion of thermal value equations is presented. Finally, conclusions are summarized.

\section{Definition of Thermal Value}

Take continuous heating furnaces, as shown in Figure 1, for an example. It can be seen that most heat in the furnaces is the chemical heat $H_{\text {che }}$ released from fuel gas's combustion. The resulting $H_{\text {che }}$ can be contained in steel to be available heat $H_{\text {ava }}$. In addition, $H_{\text {che }}$ transfers also into other points, e.g., $H_{\text {sur }}$ is lost to surroundings by thermal radiation and convection from the furnaces' external surface and to soil by conduction, $H_{\mathrm{spi}}$ runs away from the furnaces with off-gas at furnaces' door and other pores, and $H_{\text {cool }}$ is absorbed by cooling water. Much heat $H_{\text {exh }}$ also leaves with combustion products which can be used to preheat gas. Then it converts to the physical heat $H_{\text {phy }}$ of gas and flows into furnace chamber once 
again. Actually, the heat contained in discharging steel is not completely meets the expectation (the superheated part $H_{\text {sup }}$ is also one sort of heat losses, for example). Additionally, hot charging steel has an effective heat $H_{\text {cha }}$ itself.

The main purpose of heating furnaces is to heat steel to a target temperature at which the sensible heat of the steel is called target heat. Due to the loss items described above, it is impossible for each injected heat contributes to target heat completely. And the thermal value $(V)$ of a certain injected heat is defined as the rate of the part contributing to target heat to the heat injected into the furnace. It is written as

$$
V=H_{\text {tar }} / H
$$

where $H$ is the enthalpy of injected heat, and $H_{\text {tar }}$ is the part contributing to target heat of $H$.

\section{Heat Transfer Model and Thermal Value Equations}

\subsection{Continuous Heating Furnaces}

In the continuous heating furnaces (see Figure 1), gas flows in counter-flow mode with steel. The trends of gas temperature and steel temperature are given schematically in Figure 2, in which $t_{\mathrm{g}, \mathrm{i}}$ and $t_{\mathrm{g}, \mathrm{o}}$ are temperatures of gas at its inlet (furnace head) and outlet (furnace end), $t_{\mathrm{s}, \mathrm{i}}$ and $t_{\mathrm{s}, \mathrm{o}}$ are temperatures of steel at its inlet (furnace end) and outlet (furnace head), and $A_{0}$ is the total area of heat exchange.

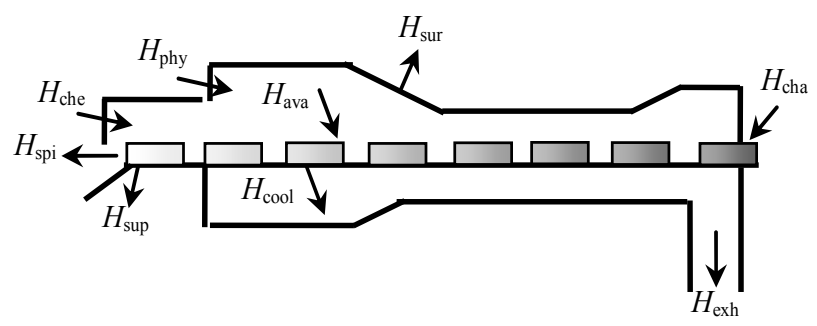

Figure 1. Schematic diagram of continuous heating furnaces.

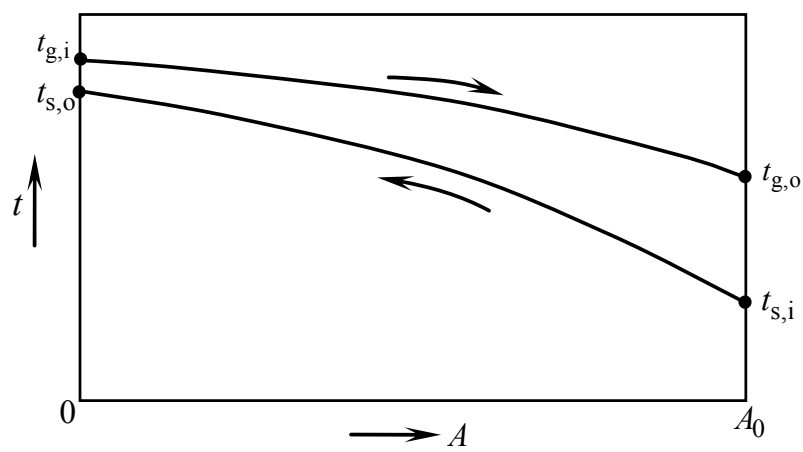

Figure 2. Model of gas-steel counter-flow heat transfer in continuous heating furnaces.
For a gas-steel counter-flow heat transfer model, as shown in Figure 2, section A is assumed as any one heat transfer section, and the heat exchange area from gas inlet to section $\mathrm{A}$ is $A$. Temperatures of gas and steel at section $\mathrm{A}$ are respectively expressed as $t_{\mathrm{g}}$ and $t_{\mathrm{s}}$. If inject a infinitesimal heat which is attached on steel at section A uniformly and steadily, local steel will have a temperature increase of $\delta t_{\mathrm{s}}$ under conditions of no side effects such as superheat; and correspondingly, steel's discharging temperature will have a temperature increase of $\delta t_{\mathrm{s}, \mathrm{o}} ;$ i.e., the $\left(\partial t_{\mathrm{s}, \mathrm{o}} / \partial t_{\mathrm{s}}\right)$ portion of the injected heat makes the steel's temperature increase and contributes to target heat, and other $\left(1-\partial t_{\mathrm{s}, \mathrm{o}} / \partial t_{\mathrm{s}}\right)$ portion returns to section $\mathrm{A}$ by way of heat exchange. When gas moving on, the $\left(\partial t_{\mathrm{g}, \mathrm{o}} / \partial t_{\mathrm{g}}\right)$ portion of heat which has returned to section $\mathrm{A}$ makes the gas's temperature increase and leaves the furnace with off-gas, and the $\left(1-\partial t_{\mathrm{g}, \mathrm{o}} / \partial t_{\mathrm{g}}\right)$ portion also returns to section A through heat exchange and takes part in the following heat transfer. Then the part contributing to target heat of injected heat at section $\mathrm{A}$ is

$$
\sum_{i=0}^{\infty}\left[\frac{\partial t_{\mathrm{s}, \mathrm{o}}}{\partial t_{\mathrm{s}}}\left(1-\frac{\partial t_{\mathrm{s}, \mathrm{o}}}{\partial t_{\mathrm{s}}}\right)^{i}\left(1-\frac{\partial t_{\mathrm{g}, \mathrm{o}}}{\partial t_{\mathrm{g}}}\right)^{i}\right]
$$

so thermal value of this injected heat can be written as

$$
V_{\mathrm{s}}=\frac{\partial t_{\mathrm{s}, \mathrm{o}}}{\partial t_{\mathrm{s}}} /\left[1-\left(1-\frac{\partial t_{\mathrm{s}, \mathrm{o}}}{\partial t_{\mathrm{s}}}\right)\left(1-\frac{\partial t_{\mathrm{g}, \mathrm{o}}}{\partial t_{\mathrm{g}}}\right)\right] .
$$

According to [5], then

$$
\begin{aligned}
\frac{\partial t_{\mathrm{g}, \mathrm{o}}}{\partial t_{\mathrm{g}}}=1-\frac{1-\exp \left[-\left(1-\frac{W_{\mathrm{g}}}{W_{\mathrm{s}}}\right) \frac{k\left(A_{0}-A\right)}{W_{\mathrm{g}}}\right]}{1-\frac{W_{\mathrm{g}}}{W_{\mathrm{s}}} \exp \left[-\left(1-\frac{W_{\mathrm{g}}}{W_{\mathrm{s}}}\right) \frac{k\left(A_{0}-A\right)}{W_{\mathrm{g}}}\right]}, \\
\text { and } \frac{\partial t_{\mathrm{s}, \mathrm{o}}}{\partial t_{\mathrm{s}}}=1-\frac{W_{\mathrm{g}}}{W_{\mathrm{s}}} \cdot \frac{1-\exp \left[-\left(1-\frac{W_{\mathrm{g}}}{W_{\mathrm{s}}}\right) \frac{k A}{W_{\mathrm{g}}}\right]}{1-\frac{W_{\mathrm{g}}}{W_{\mathrm{s}}} \exp \left[-\left(1-\frac{W_{\mathrm{g}}}{W_{\mathrm{s}}}\right) \frac{k A}{W_{\mathrm{g}}}\right]},
\end{aligned}
$$

where $k$ is over-all heat transfer coefficient of gas-steel and assumed as a constant, and $W_{\mathrm{g}}, W_{\mathrm{s}}$ are water equivalent of gas and steel, respectively. Define

$$
A=\mu A_{0}, \quad(0 \leq \mu \leq 1),
$$

and substitute Equations (2)-(4) into Equation (1), then thermal value equation for injected heat attached on steel is expressed as

$$
V_{\mathrm{s}}=\frac{1-\frac{W_{\mathrm{g}}}{W_{\mathrm{s}}} \exp \left[-\left(1-\frac{W_{\mathrm{g}}}{W_{\mathrm{s}}}\right) \frac{k A_{0}}{W_{\mathrm{g}}}(1-\mu)\right]}{1-\frac{W_{\mathrm{g}}}{W_{\mathrm{s}}} \exp \left[-\left(1-\frac{W_{\mathrm{g}}}{W_{\mathrm{s}}}\right) \frac{k A_{0}}{W_{\mathrm{g}}}\right]} .
$$


Similarly, if injected infinitesimal heat is attached on gas at section $\mathrm{A}$, the $\left(\partial t_{\mathrm{g}, 0} / \partial t_{\mathrm{g}}\right)$ portion of injected heat will make the gas's temperature increase and leave the furnace with off-gas; and other $\left(1-\partial t_{\mathrm{g}, 0} / \partial t_{\mathrm{g}}\right)$ portion will return to section A by means of heat exchange. As steel moving on, the $\left(\partial t_{\mathrm{s}, 0} / \partial t_{\mathrm{s}}\right)$ portion of the returned heat is contained in target heat, and other $\left(1-\partial t_{\mathrm{s}, 0} / \partial t_{\mathrm{s}}\right)$ portion also returns to section A by gas through counter-flow heat exchange. Then, by the same method, the thermal value $\left(V_{\mathrm{g}}\right)$ of original injected heat is rearranged as

$$
V_{\mathrm{g}}=\frac{1-\exp \left[-\left(1-\frac{W_{\mathrm{g}}}{W_{\mathrm{s}}}\right) \frac{k A_{0}}{W_{\mathrm{g}}}(1-\mu)\right]}{1-\frac{W_{\mathrm{g}}}{W_{\mathrm{s}}} \exp \left[-\left(1-\frac{W_{\mathrm{g}}}{W_{\mathrm{s}}}\right) \frac{k A_{0}}{W_{\mathrm{g}}}\right]} .
$$

Expression $\left(k A_{0} / W_{\mathrm{g}}\right)$ in Equations (5) and (6) is a criterion with function of measuring dimensionless distance $A_{0}$ using $W_{\mathrm{g}} / k$. Define

$$
S t_{\mathrm{g}}=k A / W_{\mathrm{g}}, \cdots S t_{\mathrm{g} 0}=k A_{0} / W_{\mathrm{g}} .
$$

where $S t_{\mathrm{g}}$ is the Stanton number for gas, and $S t_{\mathrm{g} 0}$ is the Stanton number for gas when heat exchange area is $A_{0}$, Equations (5) and (6) can be rewritten as

$$
\begin{gathered}
V_{\mathrm{s}}=\frac{1-\frac{W_{\mathrm{g}}}{W_{\mathrm{s}}} \exp \left[-\left(1-\frac{W_{\mathrm{g}}}{W_{\mathrm{s}}}\right)\left(S t_{\mathrm{g} 0}-S t_{\mathrm{g}}\right)\right]}{1-\frac{W_{\mathrm{g}}}{W_{\mathrm{s}}} \exp \left[-\left(1-\frac{W_{\mathrm{g}}}{W_{\mathrm{s}}}\right) S t_{\mathrm{g} 0}\right]}, \\
V_{\mathrm{g}}=\frac{1-\exp \left[-\left(1-\frac{W_{\mathrm{g}}}{W_{\mathrm{s}}}\right)\left(S t_{\mathrm{g} 0}-S t_{\mathrm{g}}\right)\right]}{1-\frac{W_{\mathrm{g}}}{W_{\mathrm{s}}} \exp \left[-\left(1-\frac{W_{\mathrm{g}}}{W_{\mathrm{s}}}\right) S t_{\mathrm{g} 0}\right]}
\end{gathered}
$$

Equations (5)-(8) are thermal value equations for continuous heating furnace; and Equations (5) and (7) are suitable for injected heat attached on steel while Equations (6) and (8) are suitable for injected heat attached on gas.

As for hot charging, it is regarded as injecting heat at steel inlet and making it be attached on cold steel; i.e., $\mu$ $=1$ and $S t_{\mathrm{g}}=S t_{\mathrm{g} 0}$. Similarly, gas preheating is upsides with injecting heat into cold gas at gas inlet, where $\mu=0$ and thus $S t_{\mathrm{g}}=0$. Define

$$
\theta=\left(t_{\mathrm{g}, \mathrm{i}}-t_{\mathrm{g}, \mathrm{o}}\right) /\left(t_{\mathrm{s}, \mathrm{o}}-t_{\mathrm{s}, \mathrm{i}}\right)=W_{\mathrm{s}} / W_{\mathrm{g}},
$$

then thermal value for hot charging $\left(V_{\text {cha }}\right)$ and gas preheating $\left(V_{\text {pre }}\right)$ are presented in Figure 3.

It can be found from Figure 3 that injected heat at higher $\theta$ has higher thermal value, when other conditions being equal, especially for lower $S t_{\mathrm{g} 0}$ and/or $\theta$; thermal value increases with increasing $\theta$, but its increase rate decreases with the continually increasing $\theta$.

\subsection{Batch-type Heating Furnaces}

Batch-type heating furnaces' structure diagram is shown in Figure 4. Consider a heat transfer model with constant gas temperature in the furnace; the steel's section temperature difference is neglected. Followed is the modified Stalk's formula:

$$
\tau_{0}=m c_{p} \ln \left[\left(t_{\mathrm{g}}-t_{0}\right) /\left(t_{\mathrm{g}}-t_{\mathrm{s}}\right)\right] /(K h F),
$$

where $\tau_{0}$ is heating time, $\mathrm{m}$ is the mass of steel, $c_{p}$ is the specific heat at constant pressure of steel, $t_{\mathrm{g}}$ is the temperature of furnace gas, and $t_{0}, t_{\mathrm{s}}$ are steel temperature at initial time and $\tau=\tau_{0}$, respectively; $K$ is the correction coefficient considering the characteristic of heat transfer inside the thick steel, $h$ is comprehensive heat transfer coefficient, and $F$ is area of steel.

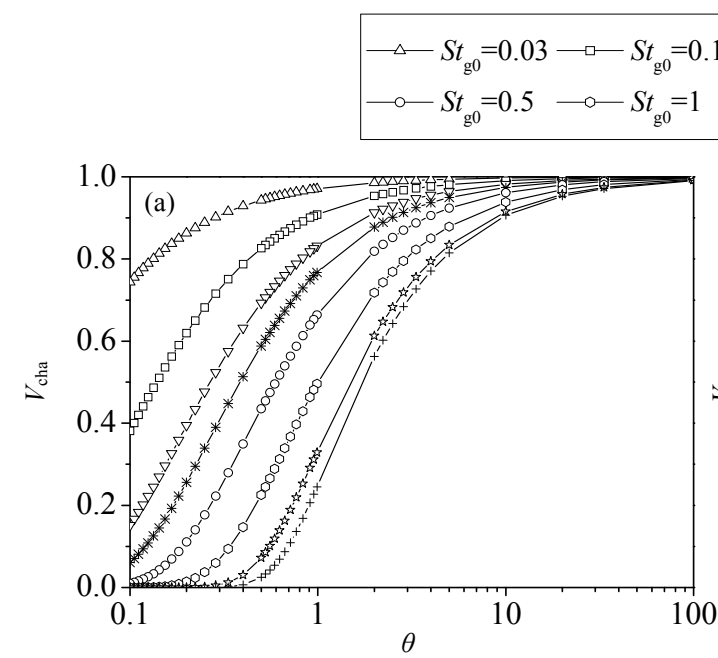

Figure 3. Thermal value corresponding to different values of $S t_{\mathrm{g} 0} \cdot$ (a) $V_{\text {cha }}$ vs. $\theta$; (b) $V_{\text {pre }}$ vs. $\theta$. 
According to Equation (9), heating curve of steel in batch-type furnaces is schematically shown in Figure 5. After injecting heat into batch-type furnace, Equation (9) can be rewritten as

$$
\tau=m c_{p} \ln \left[\left(t_{\mathrm{g}}-t_{\mathrm{s}, \mathrm{i}}\right) / t_{\mathrm{g}}-t_{\mathrm{s}, \mathrm{o}}\right] /(K h F),
$$

where $\tau$ is the heating time with heat being injected, and $t_{\mathrm{s}, \mathrm{i}}, t_{\mathrm{s}, \mathrm{o}}$ are the initial temperature and end temperature of steel with heat being injected, respectively.

Inject infinitesimal heat into the model shown in Figure 5 uniformly and steadily and make it be attached on steel so that local steel has a temperature increase of $\delta t_{\mathrm{s}, \mathrm{i}}$ from $t_{\mathrm{s}, \mathrm{i}}$ and hence the end temperature of steel increases by $\delta t_{\mathrm{s}, \mathrm{o}}$ during time-span $(\tau)$ since injecting heat. Considering other conditions unchanged, during the time $\tau$ of heating process, the $\left(\partial t_{\mathrm{s}, \mathrm{o}} / \partial t_{\mathrm{s}, \mathrm{i}}\right)$ portion of injected heat is for one part of target heat. According to the definition of thermal value, the thermal value $\left(V_{\mathrm{s}}\right)$ of the injected infinitesimal heat is written as

$$
V_{\mathrm{s}}=\partial t_{\mathrm{s}, \mathrm{o}} / \partial t_{\mathrm{s}, \mathrm{i}} .
$$

From Equations (10) and (11), it can be arrived at

$$
V_{\mathrm{s}}=\exp \left[-K h F \tau /\left(m c_{p}\right)\right] \text {. }
$$

By the same method, if the uniformly injected heat is attached on gas which has a temperature increase of $\delta t_{\mathrm{g}}$

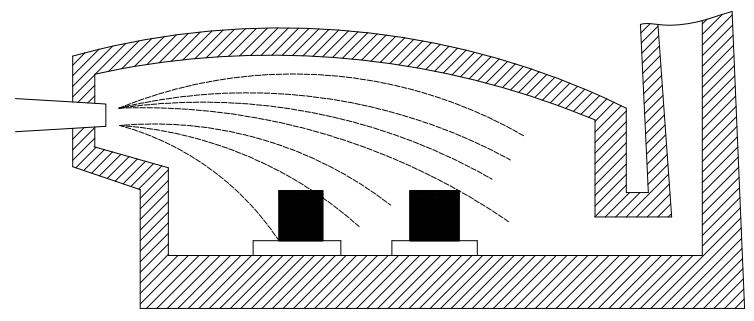

Figure 4. Schematic diagram of batch-type heating furnaces.

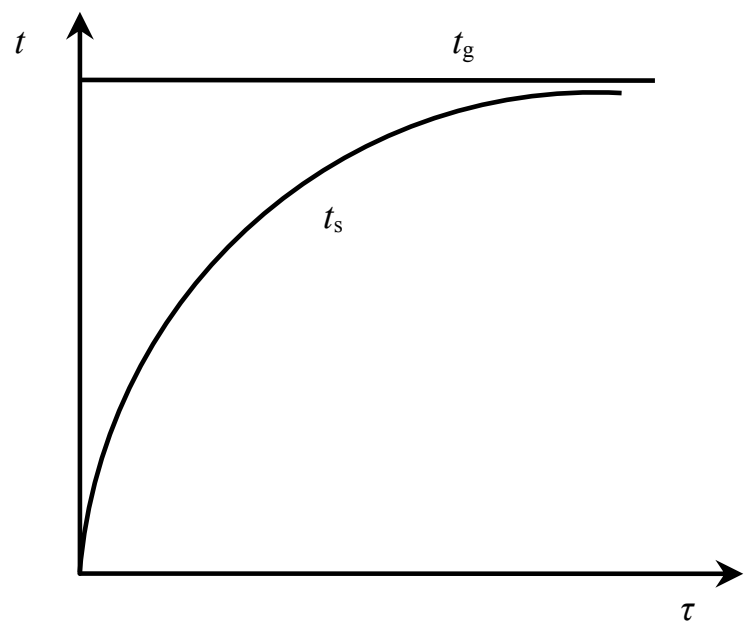

Figure 5. Model of heating process in batch-type heating furnaces. during the heating period $\tau$, and correspondingly, the end temperature of steel has increased by $\delta t_{\mathrm{s}, \mathrm{o}}$ from $t_{\mathrm{s}, \mathrm{o}}$. During heating process of time-span $\tau$, the $\left[\left(W_{\mathrm{s}} \partial t_{\mathrm{s}, \mathrm{o}}\right) /\left(W_{\mathrm{g}} \partial t_{\mathrm{g}}\right)\right]$ portion of the heat injected into gas contributes to target heat; therefore, the thermal value $\left(V_{\mathrm{g}}\right)$ of the injected infinitesimal heat is as follows:

$$
V_{\mathrm{g}}=\left[1-\exp \left[-K h F \tau /\left(m c_{p}\right)\right]\right] /\left(W_{\mathrm{g}} / W_{\mathrm{s}}\right) .
$$

Expression $\left(\mathrm{KhF \tau} /\left(m c_{p}\right)\right)$ in Equations (12) and (13) is a criterion with function of measuring dimensionless time $\tau$ using $\left(m c_{p} /(K h F)\right)$. Define

$$
S t_{\mathrm{s}}=K h F \tau /\left(m c_{p}\right),
$$

where $S t_{\mathrm{s}}$ is the Stanton number for steel, Equations (12) and (13) can be rewritten as

$$
V_{\mathrm{s}}=\exp \left(-S t_{\mathrm{s}}\right)
$$

and

$$
V_{\mathrm{g}}=\left[1-\exp \left(-S t_{\mathrm{s}}\right)\right] /\left(W_{\mathrm{g}} / W_{\mathrm{s}}\right) \text {. }
$$

Equations (12)-(15) are thermal value equations for batch-type heating furnace; and Equations (12) and (14) are suitable for injected heat attached on steel while Equations (13) and (15) are suitable for injected heat attached on gas.

Taking the heating of thin steel as an example, the relationship between thermal value and intake time is presented in Figure 6 [7]. It can be seen that injected heat attached on steel at shorter time $\tau$ (closer to the end of heating) has higher thermal value $V_{\mathrm{s}}$; and heat attached on gas at longer time $\tau$ has higher thermal value $V_{\mathrm{g}}$.

\subsection{Regenerative Heating Furnaces}

Regenerative heating furnaces have been applied and spread at home and abroad since the new century. Furnaces of this type operate on the principle of high temperature air combustion (HTAC) technology and have uniform temperature in furnace hearth. The structure diagram and its simplified model are shown in Figures 7 and $\mathbf{8}$, respectively.

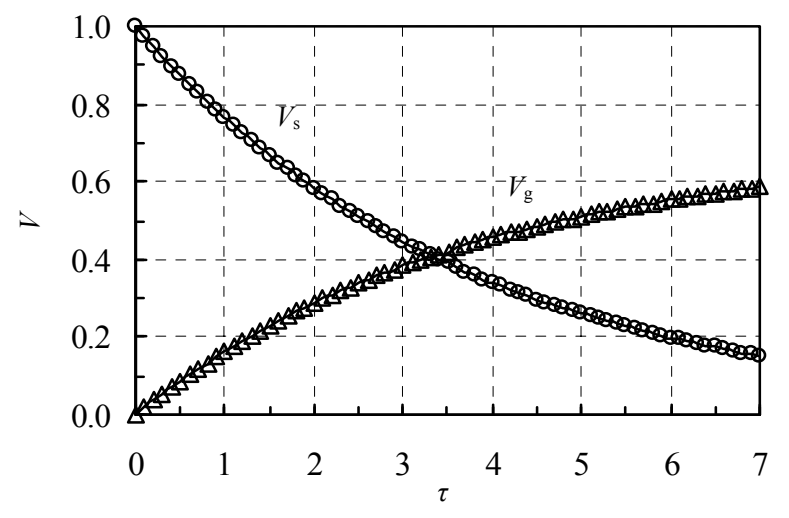

Figure 6. $\boldsymbol{V}$ vs. $\tau$. 


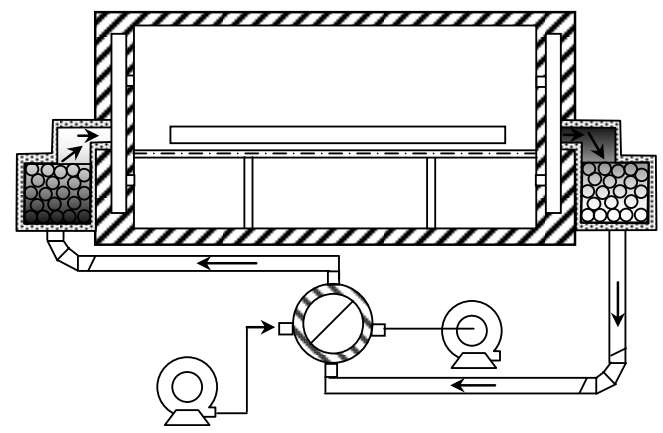

Figure 7. Schematic diagram of regenerative heating furnaces.

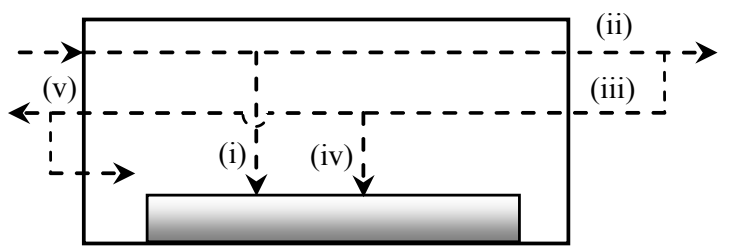

Figure 8. Energy utilization model in regenerative heating furnaces.

Inject a infinitesimal heat steadily and uniformly into the model shown in Figure 8 and make it be attached on gas at a certain section, the $\left[\left(W_{\mathrm{s}} \partial t_{\mathrm{s}, \mathrm{o}}\right) /\left(W_{\mathrm{g}} \partial t_{\mathrm{g}}\right)\right]$ portion of the injected heat (i) makes the steel's temperature increase and be contained in target heat, but other

$\left[1-\left(W_{\mathrm{s}} \partial t_{\mathrm{s}, \mathrm{o}}\right) /\left(W_{\mathrm{g}} \partial t_{\mathrm{g}}\right)\right]$ portion (ii) flows into regenerative chamber to preheat cold gas. Assume the recovery efficiency of waste heat of regenerative chamber is $\eta$, then the $\left\{(1-\eta)\left[1-\left(W_{\mathrm{s}} \partial t_{\mathrm{s}, \mathrm{o}}\right) /\left(W_{\mathrm{g}} \partial t_{\mathrm{g}}\right)\right]\right\}$ portion of the heat entering regenerative chamber is off the furnace with waste gas while the $\left\{\eta\left[1-\left(W_{\mathrm{s}} \partial t_{\mathrm{s}, \mathrm{o}}\right) /\left(W_{\mathrm{g}} \partial t_{\mathrm{g}}\right)\right]\right\}$ portion (iii) returns with preheated gas and continuous to take part in the heat transfer process, viz., processes (iv) and (v). Then the part contributing to target heat of the original injected heat is

$$
\sum_{i=0}^{\infty}\left[\eta^{i}\left(1-\frac{W_{\mathrm{s}} \partial t_{\mathrm{s}, \mathrm{o}}}{W_{\mathrm{g}} \partial t_{\mathrm{g}}}\right)^{i} \frac{W_{\mathrm{s}} \partial t_{\mathrm{s}, \mathrm{o}}}{W_{\mathrm{g}} \partial t_{\mathrm{g}}}\right]
$$

so the thermal value $\left(V_{\mathrm{g}}\right)$ of injected heat is

$$
V_{\mathrm{g}}=\frac{W_{\mathrm{s}} \partial t_{\mathrm{s}, \mathrm{o}}}{W_{\mathrm{g}} \partial t_{\mathrm{g}}} /\left[1-\eta\left(1-\frac{W_{\mathrm{s}} \partial t_{\mathrm{s}, \mathrm{o}}}{W_{\mathrm{g}} \partial t_{\mathrm{g}}}\right)\right] .
$$

Similarly, if the uniformly injected heat is attached on steel, which results in a temperature increase of $\delta t_{\mathrm{s}, \mathrm{i}}$ for local steel and $\delta t_{\mathrm{s}, \mathrm{o}}$ for discharging steel, the $\left(\partial t_{\mathrm{s}, \mathrm{o}} / \partial t_{\mathrm{s}, \mathrm{i}}\right)$ portion of the injected heat will be part of target heat and other $\left(1-\partial t_{\mathrm{s}, \mathrm{o}} / \partial t_{\mathrm{s}, \mathrm{i}}\right)$ portion will enter regenerative chamber with gas. For the heat passing through regenerative chamber, its $\left[(1-\eta)\left(1-\partial t_{\mathrm{s}, \mathrm{o}} / \partial t_{\mathrm{s}, \mathrm{i}}\right)\right]$ portion losses while other $\left[\eta\left(1-\partial t_{\mathrm{s}, \mathrm{o}} / \partial t_{\mathrm{s}, \mathrm{i}}\right)\right]$ portion returns to furnace hearth with preheated gas. So, the thermal value $\left(V_{\mathrm{s}}\right)$ of the in- jected heat is written as

$$
V_{\mathrm{s}}=\frac{\partial t_{\mathrm{s}, \mathrm{o}}}{\partial t_{\mathrm{s}, \mathrm{i}}}+\eta\left(1-\frac{\partial t_{\mathrm{s}, \mathrm{o}}}{\partial t_{\mathrm{s}, \mathrm{i}}}\right) \frac{W_{\mathrm{s}} \partial t_{\mathrm{s}, \mathrm{o}}}{W_{\mathrm{g}} \partial t_{\mathrm{g}}} /\left[1-\eta\left(1-\frac{W_{\mathrm{s}} \partial t_{\mathrm{s}, \mathrm{o}}}{W_{\mathrm{g}} \partial t_{\mathrm{g}}}\right)\right]
$$

Although regenerative heating furnaces belong to continuous furnaces in steel transport style, the energy using situation is alike to batch-type furnaces since the temperature of combustion products is uniform in the whole furnace hearth [8], because which it has no difference whether steel taps off from feed door or from discharge door and regenerative furnaces have shared characteristics of both continuous ones and batch-type ones. Combining with Equations (10), Equations (16) and (17) can be rewritten as

$$
V_{\mathrm{g}}=\frac{1-\exp \left(-S t_{\mathrm{s}}\right)}{\frac{W_{\mathrm{g}}}{W_{\mathrm{s}}}(1-\eta)+\eta\left[1-\exp \left(-S t_{\mathrm{s}}\right)\right]},
$$

and

$$
V_{\mathrm{s}}=\frac{\frac{W_{\mathrm{g}}}{W_{\mathrm{s}}}(1-\eta) \exp \left(-S t_{\mathrm{s}}\right)+\eta\left[1-\exp \left(-S t_{\mathrm{s}}\right)\right]}{\frac{W_{\mathrm{g}}}{W_{\mathrm{s}}}(1-\eta)+\eta\left[1-\exp \left(-S t_{\mathrm{s}}\right)\right]} .
$$

Equations (18) and (19) are thermal value equations for regenerative heating furnaces; and Equation (18) is suitable for injected heat attached on gas while Equation (19) is suitable for injected heat attached on steel.

From Equation (18) and (19), it can be got

$$
\frac{\partial V_{\mathrm{g}}}{\partial \tau}=\frac{\partial V_{\mathrm{g}}}{\partial S t_{\mathrm{s}}} \cdot \frac{\partial S t_{\mathrm{s}}}{\partial \tau} \propto \frac{W_{\mathrm{g}}}{W_{\mathrm{s}}}(1-\eta) \frac{S t_{\mathrm{s}}}{\tau} \exp \left(-S t_{\mathrm{s}}\right)>0,
$$

and

$$
\frac{\partial V_{\mathrm{s}}}{\partial \tau}=\frac{\partial V_{\mathrm{s}}}{\partial S t_{\mathrm{s}}} \cdot \frac{\partial S t_{\mathrm{s}}}{\partial \tau} \propto-\left(\frac{W_{\mathrm{g}}}{W_{\mathrm{s}}}\right)^{2}(1-\eta)^{2} \frac{S t_{\mathrm{s}}}{\tau} \exp \left(-S t_{\mathrm{s}}\right)<0 .
$$

which show that if injected heat is attached on gas, the higher $\tau$, the higher $V_{\mathrm{g}}$, and that if injected heat is attached on steel, the lower $\tau$, the higher $V_{\mathrm{s}}$; thereby, directing at higher thermal value, the supply of heat should be more at early stage and less at late stage.

The thermal value may be different even though the equivalent injected heat, depending on the intake time. Transition time $\left(\tau^{*}\right)$ is calculated by

$$
\tau^{*}=m c_{p} \ln \left(1+W_{\mathrm{g}} / W_{\mathrm{s}}\right) /(K h F) .
$$

Given the property of continuous operating, the time $\tau$ here also represents the location of steel. Correspondingly, the transition location (along steel's moving direction) $l^{*}$ is

$$
l^{*}=l \frac{\tau^{*}}{\tau}=\frac{m c_{p}}{K h F \tau} \ln \left(1+\frac{W_{\mathrm{g}}}{W_{\mathrm{s}}}\right)=S t_{\mathrm{s}} \ln \left(1+\frac{W_{\mathrm{g}}}{W_{\mathrm{s}}}\right),
$$




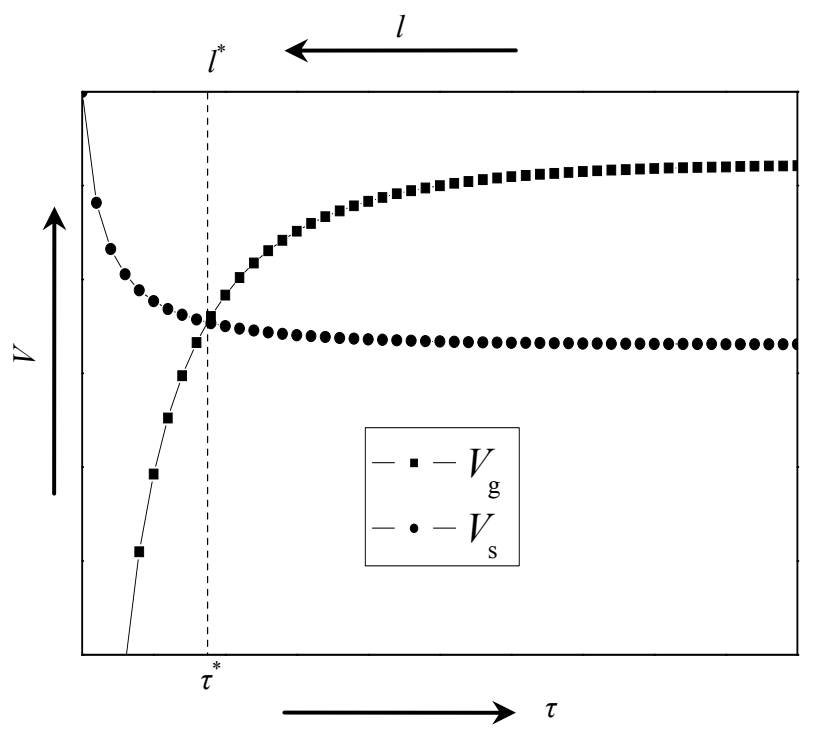

Figure 9. $V$ vs. $\tau$ and $l$.

where $l$ is the effective length of furnace.

Distinguished from continuous heating furnaces, thermal value of heat attached on steel is higher than that on gas when $l>l^{*}$ for regenerative heating furnaces, and thermal value of heat attached on steel is lower than that on gas when $l<l^{*}$ (shown in Figure 9).

\section{Conclusion}

By modeling the heat transfer processes in metallurgical furnaces, thermal value equations of continuous, batchtype, and regenerative heating furnaces are derived for evaluating their energy utilization degree. Based on the detailed derivation and discussion of thermal value equations, it can be concluded that thermal value increases with increasing temperature of preheated gas or with hot charging for continuous heating furnaces. Injecting heat into batch-type heating furnaces to be attached on steel, thermal value is higher when intake time is closer to the end of heating; while to be attached on gas, thermal value is higher when closer to the time for supplying gas. For regenerative heating furnaces, to obtain higher thermal value, the supply of heat should be more at early stage and less at late stage.

\section{Acknowledgements}

This work is supported by the Fundamental Research Funds for the Central Universities (No.N090602007), China. The corresponding author also owes great thanks to Prof. Shizheng Ren for his excellent advices.

\section{REFERENCES}

[1] Z. W. Lu, "Flame Furnace," Metallurgical Industry Press, Beijing, 1995.

[2] W. H. Chen, Y. C. Chung and J. L. Liu, "Analysis on Energy Consumption and Performance of Reheating Furnaces in a Hot Strip Mill," International Communications in Heat and Mass Transfer, Vol. 32, No. 5, 2005, pp. 695-706. doi:10.1016/j.icheatmasstransfer.2004.10.019

[3] C. L. Hou, G. B. Wang and J. Zhang, "Characteristics of Walking-Beam Reheating Furnace Applied in Continuous Casting and Rolling Line of Guofeng," Steel Rolling, Vol. 25, No. 4, 2008, pp. 26-27.

[4] W. Q. Sun, J. J. Cai and G. W. Xie, "Application Research on Energy-Saving of Continuous Heating Furnaces Based on Thermal Value Theory," Proceedings of 1 st International Conference on Applied Energy, Hong Kong, 5-7 January, 2009, pp. 614-620.

[5] J. J. Cai, W. Q. Sun and G. W. Xie, "Thermal Value Theory and Its Application to Energy-Saving for Continuous Heating Furnace," Journal of Northeastern University (Natural Science), Vol. 30, No. 10, 2009, pp. 1454-1457.

[6] S. Z. Ren, "Heat Transfer," Metallurgical Industry Press, Beijing, 2007.

[7] W. Q. Sun, J. J. Cai, T. Du and C. Wang, "Research on Effective Utilization Degree of Energy in Batch-Type Furnace Based on Thermal Value Theory", Proceedings of 2009 International Conference on Energy and Environment Technology, Guilin, 16-19 October, 2009, Vol. 1, pp. 794-797. doi:10.1109/ICEET.2009.198

[8] W. Trinks and M. H. Mashinney, "Industrial Furnaces," 5th Edition, John Wiley \& Sons Inc., New York, 1961. 